\title{
Conf-9506192-3
}

UCRL-JC-120309

PREPRINT

\section{A Practical Microgripper by Fine Alignment, Eutectic Bonding and SMA Actuation}

\author{
Abraham P. Lee \\ Dino R. Ciarlo \\ Peter A. Krulevitch \\ Stacy Lehew \\ Jimmy Trevino \\ M. Allen Northrup
}

This paper was prepared for submittal to

Transducers 95, Stockholm, Sweden

June 25-29, 1995

April 21, 1995

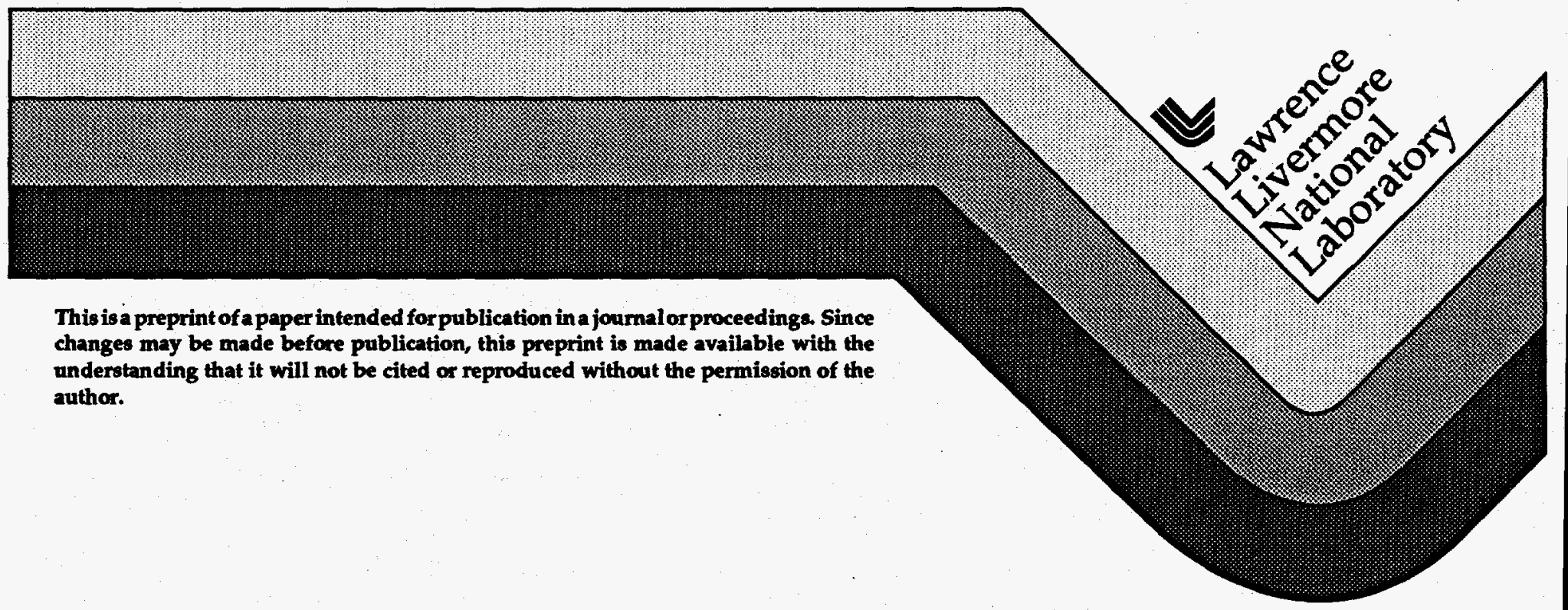

This is a preprint of a paper intended for publication in a journal or proceedinga. Since changes may be made before publication, this preprint is made available with the understanding that it will not be cited or reproduced without the permission of the author. 


\section{DISCLAIMER}

This document was prepared as an account of work sponsored by an agency of the United States Government. Neither the United States Government nor the University of California nor any of their employees, makes any warranty, express or implied, or assumes any legal liability or responsibility for the accuracy, completeness, or usefulness of any information, apparatus, product, or process disclosed, or represents that its use would not infringe privately owned rights. Reference herein to any specific commercial product, process, or service by trade name, trademark, manufacturer, or otherwise, does not necessarily constitute or imply its endorsement, recommendation, or favoring by the United States Government or the University of California. The views and opinions of authors expressed herein do not necessarily state or reflect those of the United States Government or the University of California, and shall not be used for advertising or product endorsement purposes. 


\section{DISCLAIMER}

Portions of this document may be illegible in electronic image products. Images are produced from the best available original document. 


\title{
A PRACTICAL MICROGRIPPER BY FINE ALIGNMENT, EUTECTIC BONDING AND SMA ACTUATION
}

\author{
Abraham P. Lee, Dino R. Ciarlo, Peter A. Krulevitch, Stacy Lehew, Jimmy Trevino, and M. Allen Northrup \\ Lawrence Livermore National Laboratory (LLNL), Microtechnology Center \\ P.O.Box 808, L-222, Livermore, CA 94551, U.S.A.
}

\begin{abstract}
SUMMARY
A microgripper with a large gripping force, a relatively rigid structural body, and flexibility in functional design is presented. The actuation is generated by Ni-Ti-Cu shape memory alloy (SMA) films and the stress induced can deflect each side of the microgripper up to $55 \mu \mathrm{m}$ for a total gripping motion of $110 \mu \mathrm{m}$. When fully open, the force exerted by the film corresponds to a $40 \mathrm{mN}$ gripping force on the tip of the gripper.
\end{abstract}

\section{BACKGROUND}

Although microgrippers have been demonstrated in the past [1-6] , they have mostly been either small in gripping force, low in structural rigidity, relatively small in opening displacements, or inflexible in the design parameters. Furthermore, many of the designs could not function well in a liquid environment either due to the high temperature required for activation or the high surface tension forces of the liquid limiting the gripping capability. These issues have prevented a practical microgripper from being generated.

The objective of this project is to develop a microgripper that can be locally actuated at low temperatures $\left(<100^{\circ} \mathrm{C}\right)$, with large gripping force $(>1 \mathrm{mN})$ and high structural rigidity. The capability to lock the target gripping object is another desirable feature to ensure that frictional force, which is often unpredictable, is not the only means of securing the grip.

The microgripper presented in this paper is fabricated by aligning and selectively eutectic bonding [8] two pre-processed silicon wafers and dicing up the individual microgripper structures. The process involves bulk silicon etching with double-sided alignment, precision depth-controlled sawing, and fine alignment for eutectic bonding. The fabrication process allows the designer some fiexibility in shaping the gripping jaws as specified by the object to be gripped. Also, batch fabrication allows for highly automated processing and reduces manufacturing costs. Ni-Ti-Cu shape memory alloy (SMA) films are deposited to generate low temperature, high force actuation. This type of SMA film [7] can generate actuation stresses up to $500 \mathrm{MPa}$ at transformation temperatures between $30^{\circ} \mathrm{C}$ to $70^{\circ} \mathrm{C}$. This is a lower temperature range than all thermal bimorphic microgrippers that have been published. At present, the microgripper is actuated by external heating and a video tape is prepared to demonstrate the opening and closing motions. Applications for the microgripper include assembling small parts for manufacturing, minimally-invasive in vivo biopsy tissue sampling, catheter-based endovascular therapeutic procedures, and remote handling of small particles in extreme environments (high/low pressures, hazardous fluids).

\section{DESIGN AND FABRICATION}

The microfabrication process can be categorized into bulk micromachining, fine alignment, eutectic bonding and $\mathrm{Ni}$-Ti-Cu SMA thin film deposition. Figure 1 shows

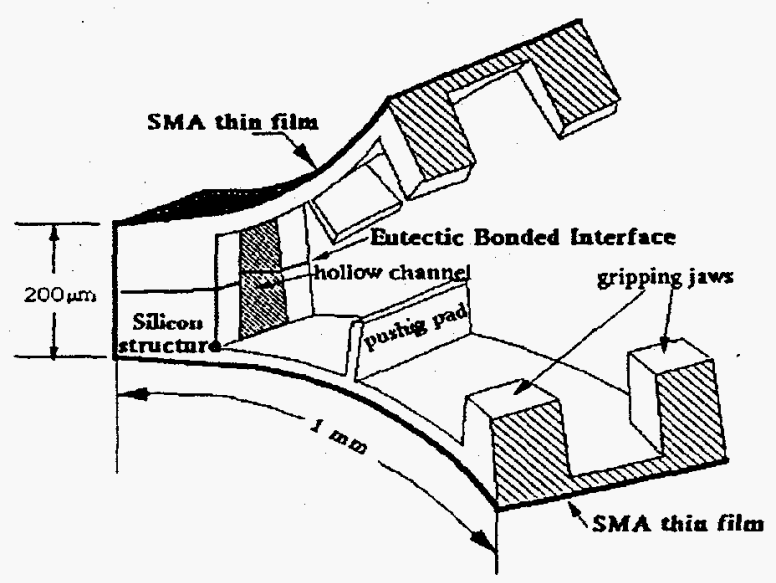

Figure 1. Three-dimensional schematic of micrgripper.

a schematic of an LLNL silicon microgripper and Fig. 2 is an SEM micrograph of a completed device. The microgripper is $1000 \times 200 \times 380 \mu^{3}$ in dimension. Each silicon cantilever is $12.5 \mu \mathrm{m}$ thick and $5 \mu \mathrm{m} \mathrm{Ni-Ti-}$ Cu SMA thin films [7] are deposited on both sides of the microgripper for actuation. The pushing pad is designed to assist in releasing the gripped object by pushing forward as the gripper is opened. This pad is $30 \mu \mathrm{m}$ wide 


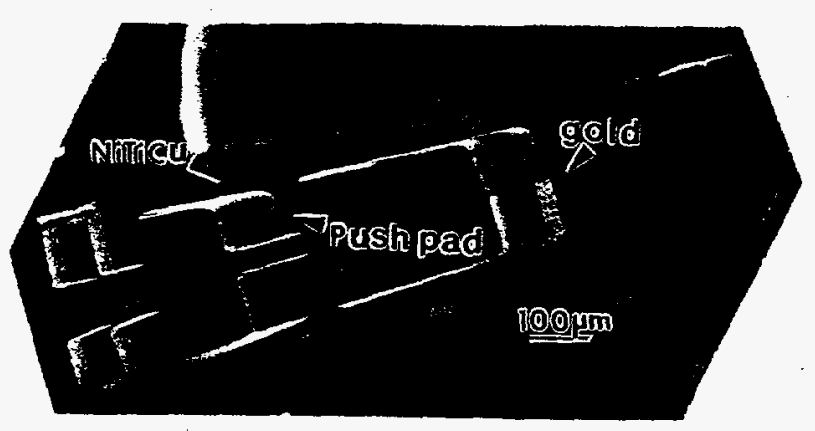

Figure 2. SEM micrograph of silicon microgripper.

while the gripping jaws are $60 \times 110 \times 100 \mu \mathrm{m}^{3}$. The hollow channel is $110 \mu \mathrm{m}$ wide. The gripping jaws, pushing pads, and hollow channel are shaped by a combination of precision sawing and bulk machining of silicon. The connection of the microgripper to external leads and milli- end effectors, requires assembly and there is ongoing effort to develop assembly and packaging techniques.

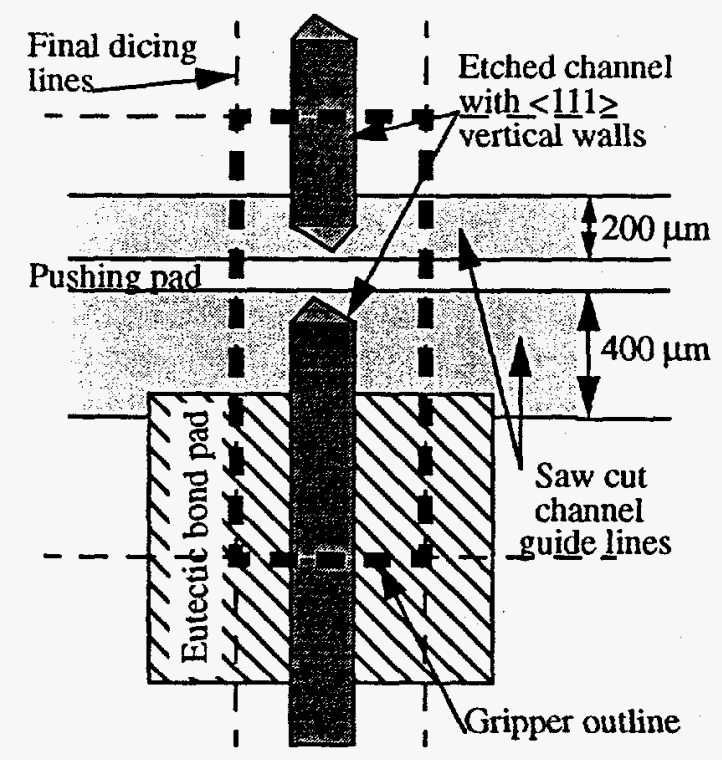

Figure 3. Illustration of the top view of a single wafer process.

Figure 3 illustrates the top-view of one half of a microgripper processed on a wafer. This process starts with two $100 \mu \mathrm{m}$ thick (110) p-type wafers, which were ground and polished from $200 \mu \mathrm{m}$ thick wafers. The common masking film for patterning and etching silicon was $1000 \AA ̊$ of silicon nitride.

A test pattern is essential to identify the exact (111) plane as opposed to the wafer flat, which is typically offset $2^{\circ}-3^{\circ}$. Alignment targets are imprinted on the wafer using this crystal plane identifying pattern to ensure the subsequent aligning to the exact crystal planes. Two types of alignment targets must be defined, one to carry out front-to-back alignment and another etched through the wafers to provide holes for precise pin alignment for eutectic bonding (see Fig. 4). Dicing lines ( $2 \mu \mathrm{m}$ deep) are then patterned on the backside of the wafer. On the front side, saw cut channel guide lines (Fig. 3) are patterned for the precision saw to form the silicon cantilevers and the pushing pad. These patterns are imprinted by etching into the silicon $1 \mu \mathrm{m}$. After reapplying the masking silicon nitride, lithography is carried out for the gripping jaws and the hollow channel. The wafers are then etched in $44 w t \% \mathrm{KOH}$, creating vertical walls $85 \mu \mathrm{m}$ deep. The silicon nitride mask is then stripped and ready for the precision saw. The precision saw used is a model 780 by Kulicke \& Soffa, with positioning accuracy as high as $2.5 \mu \mathrm{m}$. Precision sawing is chosen to avoid the anisotropic etching limitations of (110) silicon that does not allow vertical-wall etch channels $90^{\circ}$ apart without careful corner compensation and sacrifice of finished surfaces. Since the width of the two cut channels are $200 \mu \mathrm{m}$ and $400 \mu \mathrm{m}$, the blade selected is $200 \mu \mathrm{m}$ thick. The wider cut channel $(400 \mu \mathrm{m})$ is formed by making two adjacent saw cuts. The saw is indexed to leave a pushing pad width of $30 \mu \mathrm{m}$.

The two identical wafers are now ready for bonding. The process for selective eutectic bonding is described in detail in [8]. By aligning the shadow mask to the gripper patterns, a selective bond pad can be defined as in Fig. 3 . Through this shadow mask, $500 \AA$ of titanium followed by $1 \mu \mathrm{m}$ of gold is evaporated. The titanium serves as a diffusion barrier so that when an opposing silicon wafer is brought into contact, eutectic Au-Si will be formed only on this bare silicon wafer. The wafers were pressurized together and held in low vacuum (nominally $10^{-4}$ torr) and soaked at $380^{\circ} \mathrm{C}$ for 3 minutes. The Au-Si bond strength was measured in an instron pull test, where the eutectic bond pads were pulled and failed at a pull stress of $5.5 \mathrm{GPa}$. The eutectic bond areas were intact, as fracturing of the silicon surrounding the bond areas occurred in the process.

Mechanical alignment using precise diameter pins was applied to ensure controlled processing and prevent shattering of the fragile thin wafers. Figure 4 illustrates the pin-alignment technique.

The bonded pair of wafers is now ready for the SMA thin film deposition. The material chosen is $\mathrm{Ni}-\mathrm{Ti}-\mathrm{Cu}$, and the sputtering technique described in [7] was used to identify the ideal composition for our application. In brief, three separate targets are used to sputter the alloy such that the power can be individually controlled to actively determine the alloy composition. Then a single target is generated to match this composition. The film is deposited on two sides sequentially so that one side is annealed 


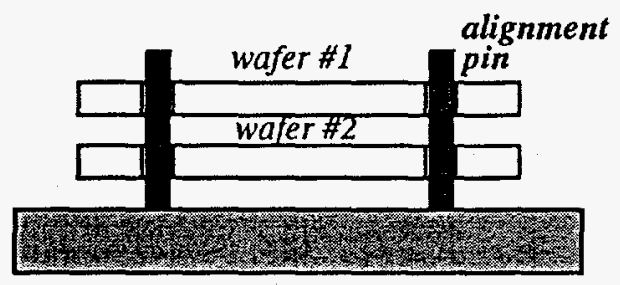

Figure 4. Mechanical alignment for eutectic bonding using alignment pins.

twice at $505^{\circ} \mathrm{C}$. This is not ideal since the film deposited first must undergo a second thermal cycle at $505^{\circ} \mathrm{C}$. An improvement in the future would be to deposit SMA before eutectic bonding. The final step is to dice up the individual microgrippers. The processing sequence is summarized below.

(a) pattern crystal plane test marks, alignment targets and alignment holes.

(b) pattern saw cut channel guide lines.

(c) pattern silicon etch channels following the (111) plane direction.

(d) anisotropic etching of the silicon etch channels by $\mathrm{KOH}$.

(e) shadow mask alignment to wafer and deposition of Ti/Au film.

(f) mechanical pin alignment and eutectic bonding at $380^{\circ} \mathrm{C}$ ( 3 mins) and $10^{-4}$ torr.

(g) sputter deposition of $\mathrm{Ni}-\mathrm{Ti}-\mathrm{Cu}$ films on both sides (2 runs) with in situ annealing at $505^{\circ} \mathrm{C}$.

(f) dice up individual microgrippers.

\section{ACTUATION OF THE MICROGRIPPER}

The microgripper is actuated using dc magnetron sputter deposited nickel-titanium-copper shane memory film. Shape memory actuation is based on a crystalline phase transformation in which the low temperature phase (martensite) is easily and reversibly deformable via twins, while the high temperature phase (austenite) has one rigid configuration [9]. The $\mathrm{Ni}_{42} \mathrm{Ti}_{50} \mathrm{Cu}_{8}$ alloy transforms just above body temperature $\left(37^{\circ} \mathrm{C}\right)$, making it useful for implantable medical devices, and has a narrower hysteresis (see Fig. 5) than binary nickel-titanium, resulting in increased efficiency and faster response time. Furthermore, the addition of copper makes the transformation temperature less sensitive to film composition [7].

In this application, actuation occurs by the recovery of tensile residual stress in the shape memory film, as shown by the data in Fig. 5 which was obtained by measuring substrate curvature as a function of temperature. The curvature change induced by the $\mathrm{Ni}$ - $\mathrm{Ti}-$ $\mathrm{Cu}$ film on a silicon wafer is measured by a Tencor
FLX-2320 laser system. This curvature is then translated into stress using the modified Stoney's equation [10]. The film, which is deposited near $500^{\circ} \mathrm{C}$, develops a tensile thermal stress as it is cooled after deposition. When cooled below the temperature at which the martensitic transformation starts, $\mathrm{M}_{s}$, the thermal stress in the film can relax by twin-related deformation. This tensile thermal stress can be recovered by re-heating the film. Thus, the silicon gripper cantilevers act as bias springs which are opened by the contracting shape memory film when heated, then deflect back to a neutral position and stretch the shape memory film when cooled. Films with up to $500 \mathrm{MPa}$ recoverable stress $\left(\sigma_{\mathrm{r}}\right)$ have been deposited, but the film on the grippers presented here have $\sigma_{\mathrm{r}}=375 \mathrm{MPa}$.

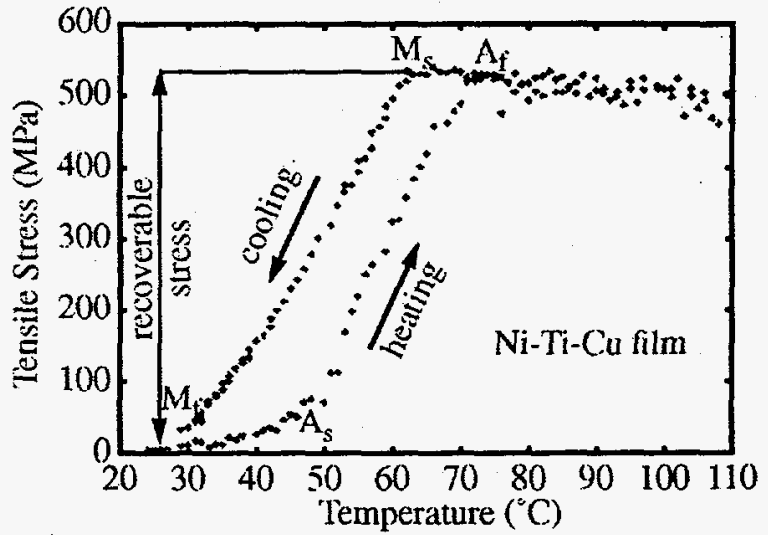

Figure 5. Substrate curvature hysteresis loop. $M_{s}, M_{f}$, $A_{s}$, and $A_{f}$ designate the martensite and austenite start and finish temperatures.

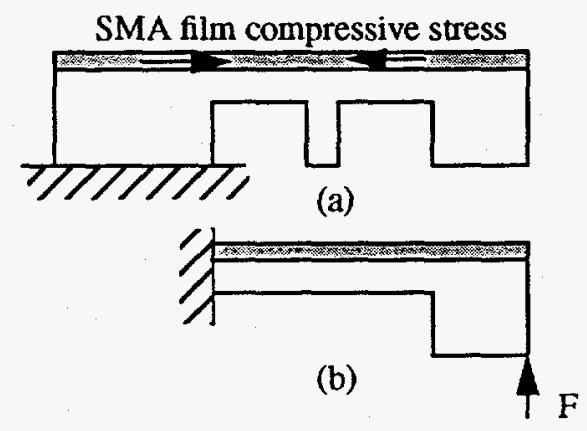

Figure 6. llustration of gripping force model.

Figure 6 illustrates the simple mechanical models used for evaluating the gripping force induced by the Ni-Ti$\mathrm{Cu}$ film (Fig.6a), assuming an equivalent model with an opening force at the tip (Fig.6b). By applying the bimetallic stress equations derived in [11], the relation between the $\mathrm{Ni}$ - $\mathrm{Ti}$-Cu film stress and the deflection of the gripper tip can be calculated. Figure 7 is a plot of the deflection of the tip of one side of a gripper and gives the parameters used. For a film thickness of $5 \mu \mathrm{m}$, the deflec- 
tion is calculated to be $53 \mu \mathrm{m}$. Experimental results showed the gripper opening to $55 \mu \mathrm{m}$ when fully actuated. Using the model of Fig. $6 \mathrm{~b}$, it will require $20 \mathrm{mN}$ to deflect the microgripper to $55 \mu \mathrm{m}$. Therefore a gripping force of $40 \mathrm{mN}$ is applied for a fully opened microgripper.

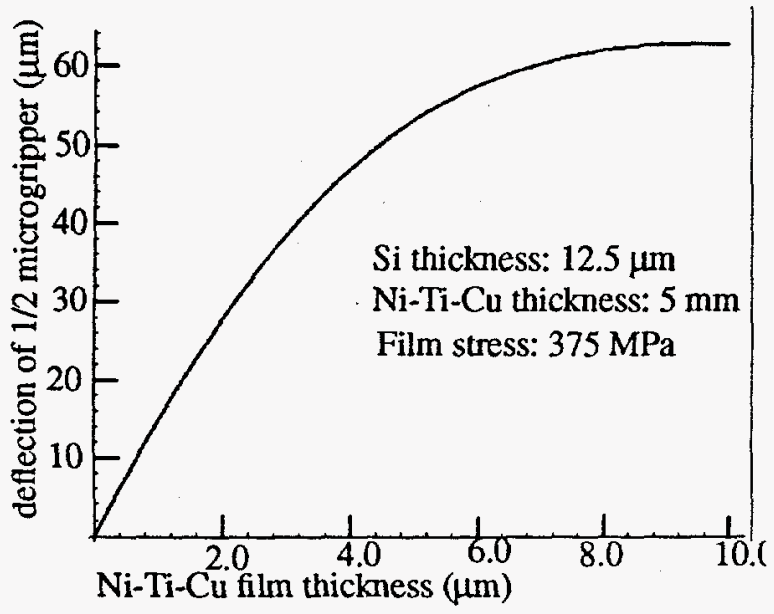

Figure 7. Microgripper jaw tip deflection vs. the film thickness of the $\mathrm{Ni}-\mathrm{Ti}-\mathrm{Cu}$.

\section{TESTING}

The heat on the microgripper is applied by an IC fabricated thin film resistor heater pad. The microgripper is placed on this heater pad and as current is applied, the heat is transferred from the heater to the Si gripper to induce phase transformation in the $\mathrm{Ni}-\mathrm{Ti}-\mathrm{Cu}$ film. The actuation was viewed through a microscope onto a video screen, and video recordings will be presented at the conference. No local measurement of the temperature was attempted at the time.

\section{DISCUSSION AND SUMMARY}

In this paper a process of a practical silicon microgripper is described. Using processes that can be automated for batch fabrication, this microgripper has large gripping force $(40 \mathrm{mN})$ and is actuated and at relatively low actuation temperatures $\left(70^{\circ} \mathrm{C}\right)$. Fine alignment, $\mathrm{Au}-\mathrm{Si}$ eutectic bonding, precision sawing, $\mathrm{Ni}$ Ti-Cu SMA deposition, as well as bulk silicon machining are the core of the process. Processes in this paper, although not standard, do not involve exotic fabrication equipment. All the individual processes could be streamlined for batch processing and therefore reduce fabrication costs.

For future developments, the outer surfaces of the gripper are being integrated with heaters and strain sensors for remote active heating and feedback control. The hollow channel has the potential for either wire connection or injection of liquids and therapeutic medicine. Another important advantage is the possibility to apply alternative actuation mechanisms on the microgripper structure, either hydraulic or simply thermal bimorphic. Many creative designs of practical microgrippers can be conceived using this basic process.

\section{ACKNOWLEDGEMENTS}

The authors would like to thank Conrad Yu and Mat Lucas for assisting in the precision alignment development. The work was performed under the auspices of the US Dept. of Energy by the Lawrence Livermore National Laboratory under contract no. W-7405-ENG48.

\section{REFERENCES}

[1] Kim, C.J., "Silicon Electromechanical Microgrippers: Design, Fabrication, and Testing", Doctoral Dissertation, University of California, November, 1991.

[2] Chu, W.-H., and Mehregany, M., "Microfabricated Tweezers with a Large Gripping Force and a Large Range of Motion", Proceedings of Solid-State Sensor and Actuator Workshop, Hilton Head, South Carolina, June 13-16, 1994.

[3] Chu, P.B. and Pister, S.J., "Analysis of closed-loop control of parallel-plate electrostatic microgrippers," Proc. 1994 IEEE International Conference on Robotics and Automation (Cat. No.94CH3375-3), vol.1., San Diego, CA, USA, May 1994, pp. 820-5

[4] Mehregany, M., Gabriel, K.J., and Trimmer, W.S., "Integrated Fabrication of Polysilicon Mechanisms," IEEE Trans. on Electron Devices, vol. ED-35, 1988.

[5] Chen, L.Y., Zhang, Z.L., Yao, J.J., Thomas, D.C., and MacDonald, N.C., "Selective Chemical Vapor Deposition of Tungsten for Microdynamic Structures," Proc. IEEE Micro Electro Mechanical Systems Workshop, Salt Lake City, UT, Feb. 1989, pp.82-87.

[6] Keller, C.G. and Howe, R.T., "Nickel-Filled Hexsil Thermally Actuated Tweezers," Transducers '95, Stockholm, Sweden, June 25-29, 1995.

[7] Krulevitch, P.A., Ramsey, P.B., Makowiecki, D.M., Lee, A.P., Johnson, G.C., and Northrup, M.A., "Mixed-Sputter Deposition of Ni-Ti-Cu Shape Memory Films," submitted to Thin Solid Films, February, 1995.

[8] Lee, A.P., Lehew, S., Yu, C., Ciarlo, D.R., Schmidt, E., and Northrup, M.A., "Selective Au-Si Eutectic Bonding for Si-Based MEMS Applications," Third Intemational Symposium on Semiconductor Wafer Bonding: Science, Technology, and Applications, Proc. 187, Meeting of Electrochemical Soc., Inc., Reno, NV, May 21-26, 1995.

[9] Engineering Aspects of Shape Memory Alloys, ed. T.W. Duerig, K.N. Melton, D. Stockel, and C.M. Wayman (ButterworthHeinemann Ldd, London, 1990).

[10] Hoffman, R.W., "The Mechanical Properties of Thin Condensed Films", Physics of Thin Films, 3 ed., Hass G. and Thun T.E., Academic Press, N.Y., 1966, p211.

[11] Timoshenko, S., "Analysis of Bimetal Thermostats," J. of Opt. Soc. Am., vol.11, 1925, pp.233-256. 